\title{
Computational Thinking Ability Training in College Computer Teaching
}

\author{
WeiguoZou
}

\section{Yancheng Institute of Industry Technology, Yancheng 224001, China}

\begin{abstract}
Computational thinking is ubiquitous, and has become a hot spot in education. As the core mission of college computer teaching, computational thinking training naturally causes widespread concern in the field of basic computer education. In this study, we propose the computational thinking formation procedural model, which reveals that computational thinking is the unity of internal and process, and the computational thinking ability training process is an important reason for the formation of computational thinking ability. And based on the factors of computational thinking training process, we construct the computational thinking - based blended teaching model.
\end{abstract}

KEYWORDS:Computational Thinking; Computer Teaching; Blended Teaching Model

\section{INTRODUCTION}

Computational thinking has existed since ancient times, and it is omnipresent. From the abacus in ancient China to the modern electronic computer, and to the currently rage internet, computational thinking content is continuing to expand, promoting the progress of human science and technology. However, for a fairly long period, computational thinking is not taken seriously by people, until 2006, when Professor Zhou Yizhenmade a clear and systemic exposition of computational thinking. Zhou explained that, computational thinking is a series of mental activities that apply the basic concepts of computer science for problem solving, system designing and human behavior understanding.

In essence, the kernel method in computational thinking is "construct", including three forms: object construction, process structure and verification structure. From the perspective of disciplinary thinking, the traditional ways of thinking closest to computer science mainly contain mathematical thinking, logical thinking and engineering thinking. Computational thinking is not a solitary thinking way, for its problem solving at different levels also reflects many features of traditional thinking ways. The relationship between computational thinking and traditional thinking is shown in Fig. 1: 


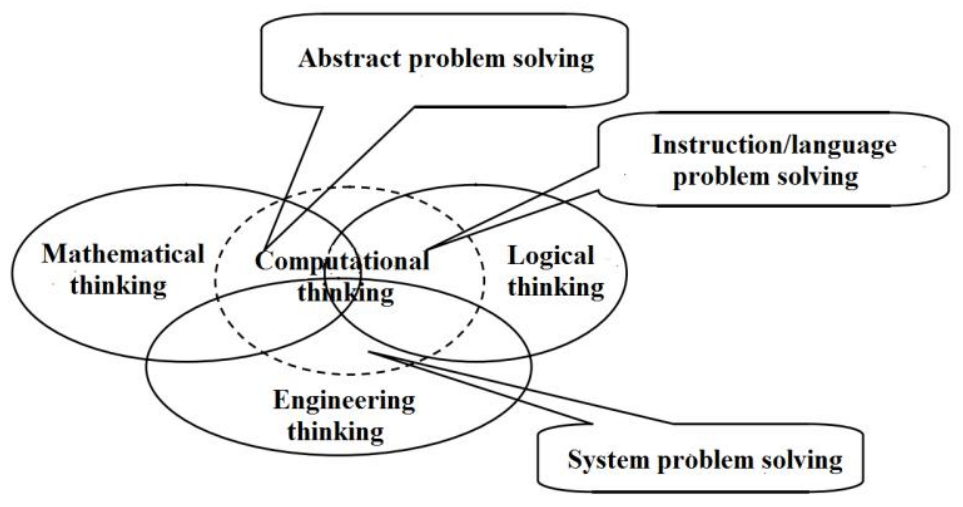

Fig.1. Relationship Between Computational Thinking And Traditional Thinking

Computational thinking contains three levels of the connotation: computational thinking consciousness, computational thinking method and computational thinking ability.

\subsection{Computational Thinking Consciousness}

Computational thinking is not a new invention, but a lasting existing thinking activity of every human being. In computer basic teaching, computational thinking cases have become more common. But the problem is that it is still unconscious thinking activity. The key is to turn the unconscious thinking into conscious thinking, and initiatively apply the computational thinking to solve problems.

\subsection{Computational Thinking Method}

Computational thinking method is the core of computational thinking. In general, there are two major types of computer thinking methods: one is from mathematics and engineering, and the other is the unique method of computer science.

In college basic computer courses, almost every concept is corresponding to one certain computational thinking. For example, Cache is preset and caching method, and multi core processor is parallel processing method. In program design courses, a variety of commonly used algorithms and problem solving methods, such as iterative method, recursive method, etc. are computational thinking methods without controversy. While in computer application courses, each course and each project is a collection of various methods of computational thinking.

\subsection{Computational Thinking Ability}

The fundamental purpose of computational thinking is to solve problems. From the perspective of computer applications, problem solving is computer application issue, e.g. to design a database application system, to create an e-commerce site, or to create a robot, etc.

The computational thinking contents cannot be covered by one mere course. Computational thinking teaching should run through all the basic computer courses in colleges. Computational thinking ability training calls for a series of computer application courses as support and development, such as multimedia technology, data technology and so on, and these courses guide students to apply computational thinking to solve a variety of professional issues. 


\section{Computational Thinking Formation Procedural Model}

For the current college students, under the support and lead of information era, their computational thinking formation process can be explicitly divided into six stages: reading, analyzing, determining, discussing, solving and reasoning, while its implicit characteristics contain skills training, ability cultivation and thinking forming. Integrating the explicit and implicit factors together, we can obtain a computational thinking formation procedural model, as shown in Fig. 2:

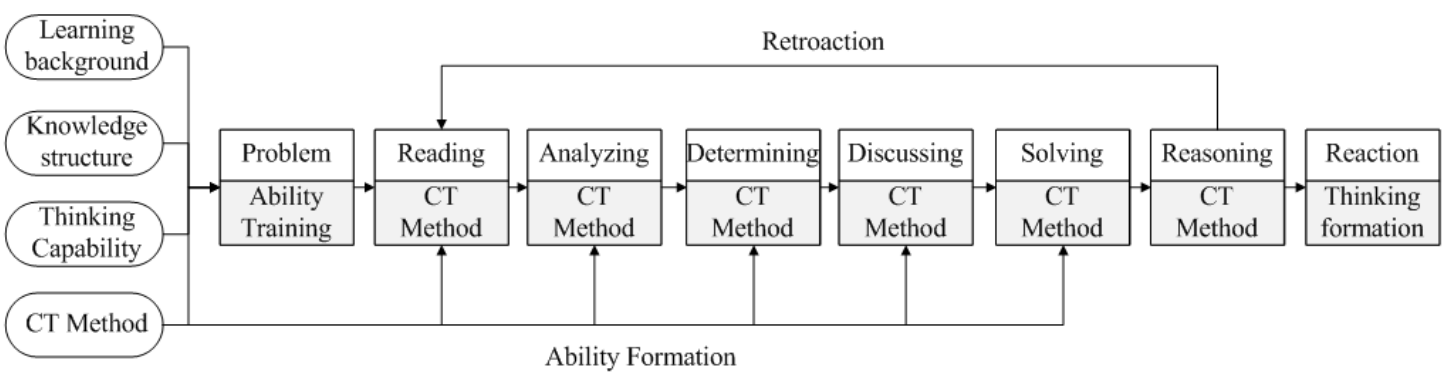

Fig.2. Computational Thinking Formation Procedural Model

From Fig. 2 above we can see that, in order to apply computational thinking method to solve the relevant problems, the students firstly need to master the knowledge structure of the problem by skill training. If students find the solution to the problem by using a series of computational thinking methods, and verify its correctness, then they will internalize this thinking method, and act on other problem solving process, thus the computational thinkingwill become a part of their skills.

Overall, computational thinking is the unity of internal and process, and the computational thinking ability training process is indeed an important reason for the formation of computational thinking ability.

\section{Computational ThinkingAbilityTraining Model}

\subsection{MOOC Teaching Platform}

MOOC is the abbreviation of four words"massive", "open", "online", "course", which is just literallyreferring to massive open online courses. It is a giant course which has a large number of participants, and taking micro class as the main content presentation form.We can understand it from four aspects, as shown in Fig. 3:

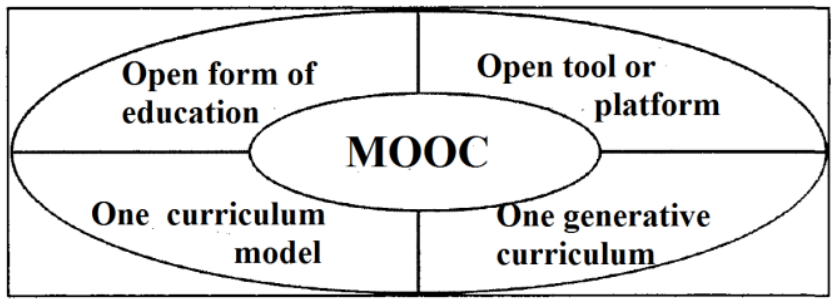

Fig.3. Connotation of MOOC

1) First, MOOC is an open form of education, without participant, time and site restrictions. All the information and resource in the courses is open, and Spread through the network.

2) Second, MOOC is an open tool or platform, where students can choose their ideal tools or platforms casually, reflecting the openness and individuation of learning environment.

3) Third, MOOC is a curriculum model, with relatively complete course structure, which the general network seminars do not have. 
4) Finally, MOOC is a generative curriculum, that is, only provide a small amount of learning materials prepared in advance, but through topic discussion, activities organization and thinking exchange, students will acquire the knowledge.

The biggest advantageof massive open online courses is a large number of free courses. MOOC is a kind of evolving mode of education, closelycombining education, entertainment and social network.

Obviously, the fragmentation teaching mode of MOOC can also bring benefits to college computer basic course teaching. Therefore, college administrators should build the MOOC learning environment platform, to better promote student learning and help improve students' computational thinking ability.

\subsection{Blended Teaching Model}

Based on the four factors of computational thinking training process: teacher, learner, learning environment and learning resources, we have constructed the computational thinking based blended teaching model, as shown in Fig. 4:

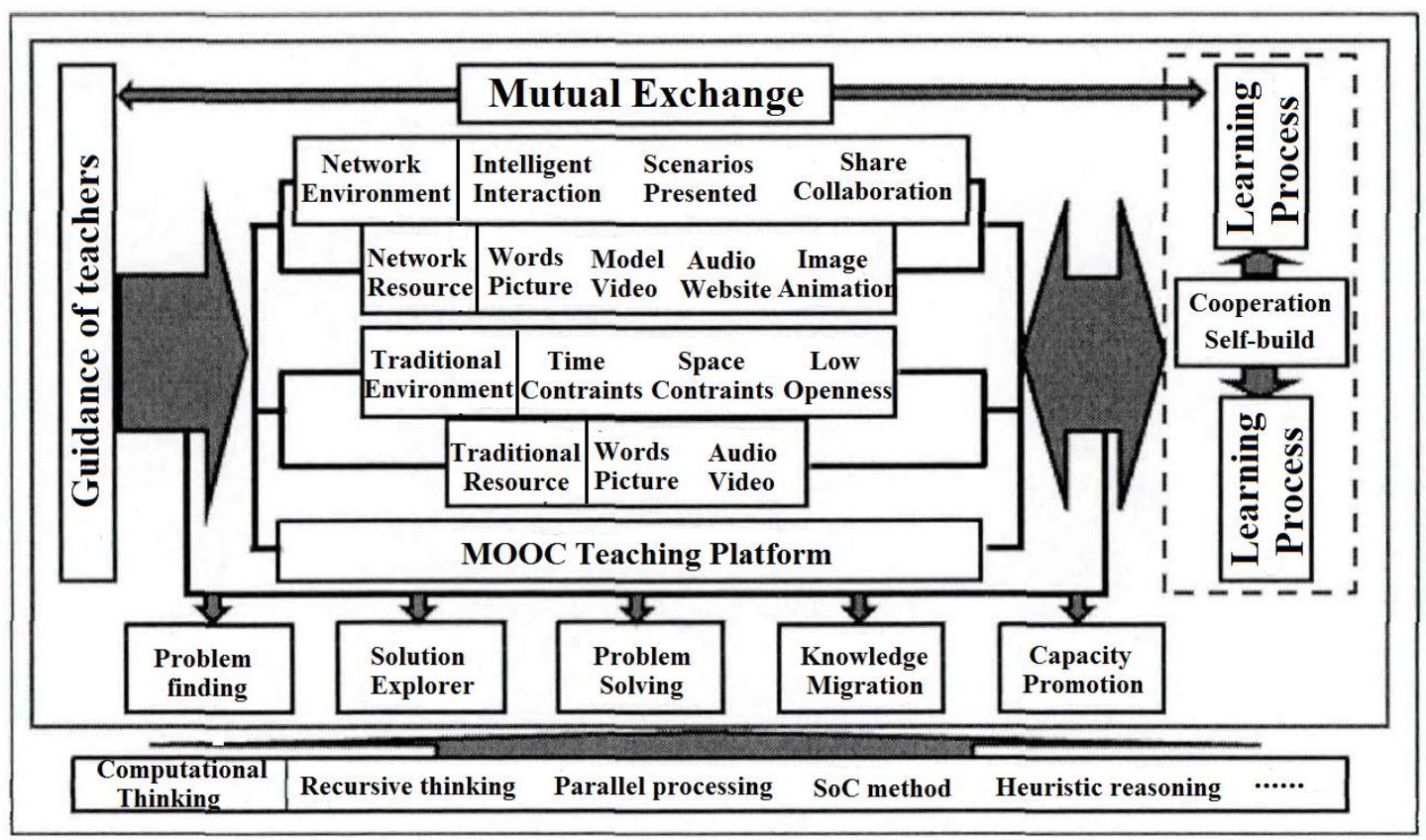

Fig.4. Blended Teaching Model Based On Computational Thinking

The blended teaching model above has associated learning process, teaching process, and various independent learning resources together through organic integration. With the guidance, help and supervision of teachers, through a series of computational thinking methods, such as recursive thinking, parallel processing, analysis concerns, abstraction and decomposition, heuristic inference, learners strive to seek the answer. In the good blended teaching environment, including traditional teaching environment, network learning environment and MOOC platform, etc. and various types of learning resources containing text, sound, pictures, images, video, etc., learners can efficiently find and solve the 
problems, and achieve the goal of expand migration and knowledge internalization.

Once the learners have grasped the computational thinking methods, and combined with their knowledge and experience acquired to construct the knowledge networks and learning framework of themselves. In addition, learners carry on mutual exchange and cooperation and meanwhile apply computational thinking methods to achieve the promotion of problem-solving skills and innovation capacity. In the process of computational thinking - based blended teaching, all the links should be underthe guidance of computational thinking concept. Through the continuous application of computational thinking methods, eventually achieve the purpose of effectively enhance students' computational thinking abilities in college computer teaching.

\section{Conclusion}

The emergence of computational thinking theory has brought huge impact on teaching process. Especially for computer science, development of computational thinking makes it no longer confined to the "tools", and makes learners no longer confined to professional and technical. Therefore, cultivation of computational thinking plays a key role in college computer teaching.

In this study, we probe the connation of computational thinking and its relationship with traditional thinking. Then we propose the computational thinking formation procedural model, which reveals that computational thinking is the unity of internal and process, and the computational thinking ability training process is an important reason for the formation of computational thinking ability. Finally, we introduce the MOOC teaching platform, and based on the factors of computational thinking training process, construct the computational thinking - based blended teaching model. This model can not only allow learners give full play to the subjective initiative in learning process, but also allow teachers effectively assist and supervise learners' learning process.

\section{REFERENCES:}

[1] Page , Gamboa . How Computers Work: Computational Thinking for Everyone[J]. Eprint Arxiv: 1301, 2013.

[2] Lancaster L. Computational thinking: a case study of Buddhist terminology using new software[J]. Journal of World Languages, 2014, 1(1):7-17.

[3] Basawapatna . Creating science simulations through Computational Thinking Patterns $[\mathrm{J}]$. Proquest Dissertations and Theses; Thesis, 2012.

[4] Anonymous. Program Design Courses Computational Thinking Ability of Students Teaching Methods[J]. Computer Knowledge and Technology, 2013.

[5] Anonymous. Towards a Blended Learning Model Based on Deep Learning Theory:Practice and Research[J]. Distance Education in China, 2013. 